\title{
Impact of rockfalls on protection measures: an experimental approach
}

\author{
J. K. Yuan ${ }^{1}$, Y. R. Li ${ }^{2,3}$, R. Q. Huang ${ }^{1}$, and X. J. Pei ${ }^{1}$ \\ ${ }^{1}$ State Key Laboratory of Geohazard Prevention and Geoenvironment Protection, Chengdu University of Technology, \\ Chengdu 610059, China \\ ${ }^{2}$ Department of Earth Sciences, Taiyuan University of Technology, Taiyuan 030024, China \\ ${ }^{3}$ AGECON Ltd., Hong Kong, China \\ Correspondence to: Y. R. Li (li.dennis@hotmail.com)
}

Received: 28 November 2014 - Published in Nat. Hazards Earth Syst. Sci. Discuss.: 9 January 2015

Revised: 31 March 2015 - Accepted: 6 April 2015 - Published: 23 April 2015

\begin{abstract}
The determination of rockfall impact force is crucial in designing protection measures. In the present study, laboratory tests are carried out by testing the weight and shape of the falling rock fragments, drop height, incident angle, platform on the slideway, and cushion layer on the protection measures to investigate their influences on the impact force. The test results indicate that the impact force is positively exponential to the weight of rockfall and the instantaneous impact velocity of the rockfall approaching the protection measures. The impact velocity is found to be dominated not only by the drop height but also by the shape of rockfall and the length of the platform on the slideway. A great drop height and/or a short platform produces a fast impact velocity. Spherical rockfalls experience a greater impact velocity than cubes and elongated cuboids. A layer of cushion on the protection measures may reduce the impact force to a greater extent. The reduction effects are dominated by the cushion material and the thickness of the cushion layer. The thicker the cushion layer, the greater the reduction effect and the less the impact force. The stiffer the buffer material, the lower the buffering effect and the greater the impact force. The present study indicates that the current standard in China for designing protection measures may overestimate the impact force by not taking into consideration the rockfall shape, platform, and cushion layer.
\end{abstract}

\section{Introduction}

The protection measures for rockfalls are mostly designed to avoid direct exposure of the protected buildings or structures to falling rock fragments. Protective flexible wire net and embankment are typical in such design (Giani et al., 2004; Labiouse, 1996; Peila et al., 1998). There is normally a strong collision behaviour when the rockfall impacts the protection measures. The maximum impact force $\left(F_{\mathrm{m}}\right)$ is, therefore, crucial during designing the protection measures. In the literature, the $F_{\mathrm{m}}$ has been found to be affected by factors, such as platform on the slope, physical and mechanical properties of falling materials, and incident angle when collision happens (Jean and Pascal, 2005; Azzoni et al., 1995; Tetsuya, 2004; Peila et al., 2007). Jean and Pascal (2005) carried out experiments and indicated that the drop height is the most important factor influencing the $F_{\mathrm{m}}$. Plassiard (2009) found that the $F_{\mathrm{m}}$ has positive correlation with the impact velocity. Stoffel and Perret (2006) carried out field trails and found that the $F_{\mathrm{m}}$ increases with the drop height. Glover et al. (2014) indicated that the rock shape is a key component and should be included in rockfall modelling. With numerical simulation, Vilajosana et al. (2008) indicated that the signals of impact force vary with density of buffer material, incident angle, weight of rockfalls, and drop height. Kishi et al. (2002) indicated that a cushion layer of sandy soil on the protection measures reduces the impact force to a great extent and the thicker the cushion layer, the greater the buffering effect. The same conclusion was also made by Kawahara and Muro (2006) and Abdul and Norimitsu (2010). Kishi (1999) 


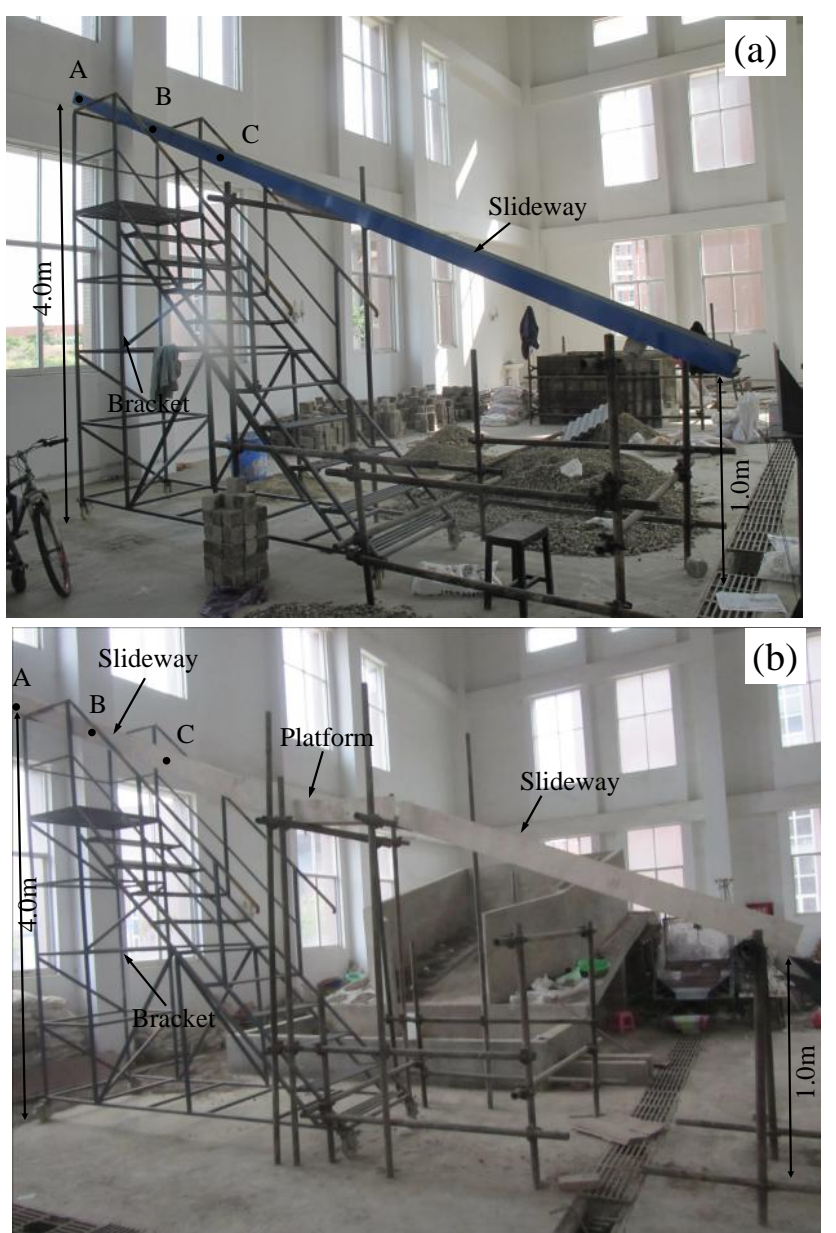

Figure 1. The rockfall devices: (a) slideway without platform and (b) slideway with a platform.

indicated that stiffness of the cushion layer influences the buffering effect as a cushion layer of high density absorbed less energy than that of low density, introducing higher impact forces. Schellenberg and Volkwein (2007) carried out rockfall tests on six reinforced concrete slabs with a cushion layer and analyzed the dynamic impact processes in the structure. Pichler et al. $(2005,2006)$ used cone-shaped objects to simulate rockfall and indicated that the free-fall penetration depth in the cushion made of gravel, the impact duration, and the impact force all were functions of the falling height. The Japan Road Association (2000) indicated that the weight of rockfalls and the drop height were the most important parameters in empirical formula of rockfall impact force.

The present study carries out laboratory tests by using the weight and shape of rockfalls, drop height, incident angle, cushion on the protected measures, and platform on the slideway as factors. The aim is to investigate and depict their influences on impact force of rockfalls.
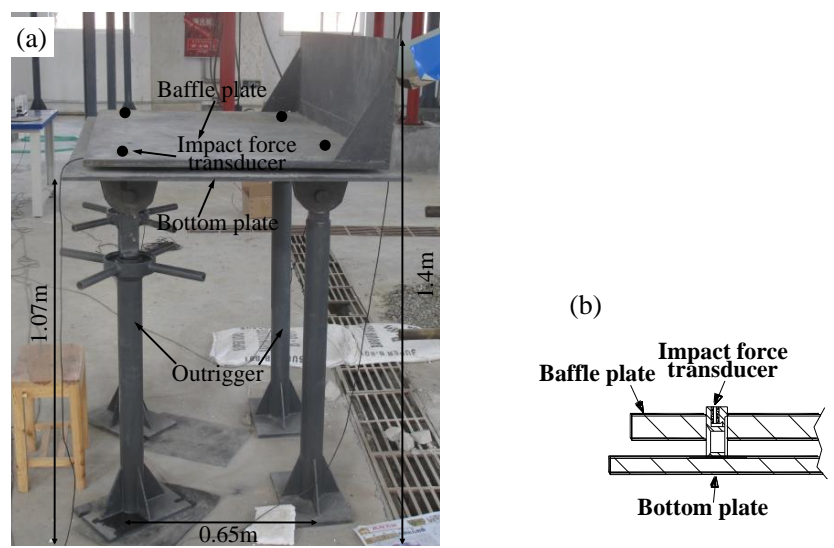

Figure 2. The protection device: (a) an overview and (b) configuration of force transducer.

\section{Test program}

\section{$2.1 \quad$ Test set-up}

The test system developed in this study consists of three parts: rockfall device, protection device, and measuring unit. As shown in Fig. 1a, the rockfall device takes a bracket structure to withstand the slideway, which is a smooth steel Ushaped channel $7 \mathrm{~m}$ long and $30 \mathrm{~cm}$ wide inside. Both ends of the slideway are placed on scaffolding brackets. An alternative device (Fig. 1b) is composed of an upper slideway, lower slideway, and a platform in-between. The length of the platform is adjustable. During tests the inner sides of the slideway and the platform were fully lubricated with a mineral oil to minimize the friction.

The protection device, being about $1.4 \mathrm{~m}$ high, consists of a baffle plate, a bottom plate, and four lifting outriggers (Fig. 2a). The baffle plate is made of steel and is $1.2 \mathrm{~m}$ long, $0.8 \mathrm{~m}$ wide, and $15 \mathrm{~mm}$ thick. The bottom plate is a $1.3 \mathrm{~m}$ long, $0.9 \mathrm{~m}$ wide, and $10 \mathrm{~mm}$ thick steel plate. The inclining angle of the baffle plate can be adjusted by lifting/lowering the outriggers to mold different incident angles. The measuring device includes four force transducers seated on the bottom plate and passing through the holes in corners of the baffle (Fig. 2a and b). During the test, the falling fragments were directed by the slideway to impact one of the transducers. As the tips of the force transducers were clear of the baffle by $5 \mathrm{~mm}$ (Fig. 2b), the transducer could grasp the full impact force without participation by the baffle. The impact forces collected by the transducer were then transmitted and stored in a data log system. In the cases where buffering effects of cushion layer were considered, the cushion materials were evenly placed on the baffle plate at a certain thickness. The test set-up simulated the impaction of rockfall on a protection measure, as shown in Fig. 3. 
Table 1. Physical and mechanical parameters of the cushion materials.

\begin{tabular}{lrrrr}
\hline Cushion material & Water content $(\%)$ & Density $\left(\mathrm{g} \mathrm{cm}^{-3}\right)$ & Elastic modulus (MPa) & Poisson's ratio \\
\hline Gravel & - & 2.12 & 50 & 0.17 \\
Sand & 7.8 & 1.56 & 13 & 0.25 \\
Clay & 21.7 & 1.27 & 5 & 0.36 \\
\hline
\end{tabular}

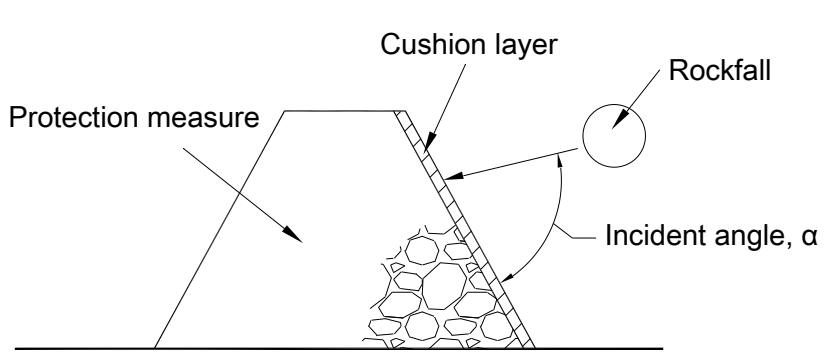

Figure 3. Schematic diagram of rockfall impacts.

\subsection{Test scheme}

Three types (sphere, cube, and rectangular cuboid in shape) of samples were adopted in the experiments (Fig. 4). Each type of samples had three specimens with the weight of 4,5 , and $6 \mathrm{~kg}$.

Points $\mathrm{A}, \mathrm{B}$, and $\mathrm{C}$ marked on the slideway were the starting points to slide (Fig. 1), representing different drop heights, i.e. $4.0,3.5$, and $3.0 \mathrm{~m}$ respectively. The impact incident angles were set to be 30,60 , and $90^{\circ}$. The buffer platform on the slideway was adjusted to be 30,60 , and $90 \mathrm{~cm}$ long. The cushion materials on the baffle plate were gravel, sand, or clay. The physical and mechanical parameters of cushion materials are listed in Table 1.

In total, 109 tests were conducted for encompassing the possible permutation and combination of factors listed in Table 2. A test with the identifier of S-6-4-90 denotes a spherical sample with the weight of $6 \mathrm{~kg}$ falling from $4 \mathrm{~m}$ and impacting the baffle plate at an incident angle of $90^{\circ}$. Similarly, a test with the identifier of C-5-3-90-2S-30 represents a cubic sample with the weight of $5 \mathrm{~kg}$ falling from $3 \mathrm{~m}$, travelling a platform of $90 \mathrm{~cm}$ long, and impacting a sand buffer layer of $2 \mathrm{~cm}$ thick at an incident angle of $30^{\circ}$. A speedometer was employed in tests to capture the instantaneous velocity of rockfall immediately approaching the baffle. It was mounted on the lower end of the slideway. Real-time measurements of the rockfall velocity can be stored in a flash memory card and displayed on a LED screen of the data log system.

\section{Results}

In the experiment, each test was repeated three times and therefore had three test results. The standard deviation of the three results ranges from 0.86 to 2.43 , which is less than $5 \%$

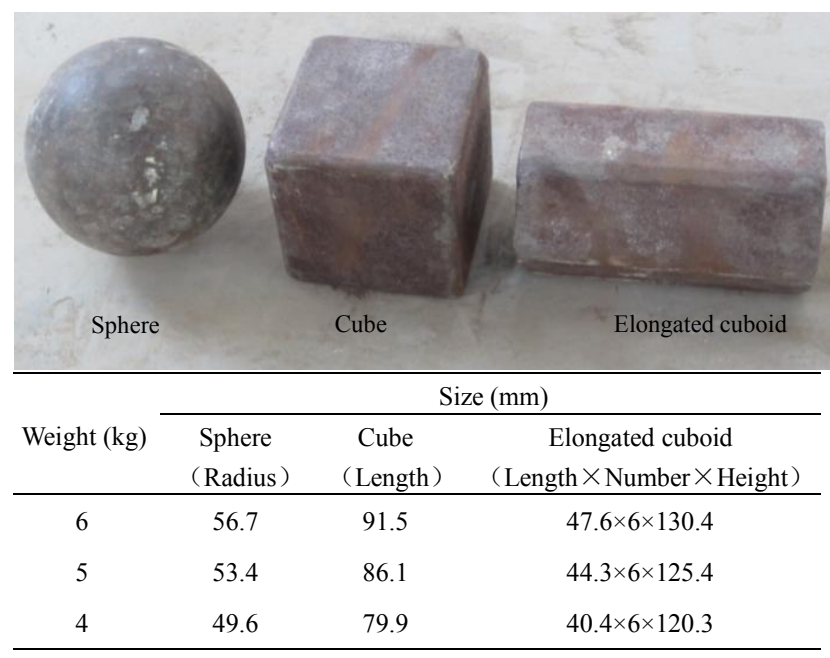

Figure 4. Shapes and sizes of the falling specimens.

Table 2. Test conditions.

\begin{tabular}{|c|c|c|c|c|}
\hline \multicolumn{3}{|l|}{ Factor } & \multicolumn{2}{|c|}{ Values } \\
\hline Rockfall shape & & Sphere & Cube & $\begin{array}{c}\text { Elongated } \\
\text { cuboid }\end{array}$ \\
\hline Weight (kg) & & 6 & 5 & 4 \\
\hline Drop height (m) & & 4.0 & 3.5 & 3.0 \\
\hline Incident angle $\left({ }^{\circ}\right)$ & & 90 & 60 & 30 \\
\hline Buffer materials & $\begin{array}{l}2 \mathrm{~cm} \text { thick } \\
4 \mathrm{~cm} \text { thick }\end{array}$ & Gravel & Sand & Clay \\
\hline \multicolumn{2}{|c|}{ Platform length $(\mathrm{cm})$} & 90 & 60 & 30 \\
\hline
\end{tabular}

of the average. This indicates a good repeatability of the tests. The average value of the three results for each test was then taken for the following discussion.

\subsection{Drop height and incident angle}

The maximum impact force $(47.7 \mathrm{kN})$ occurred in the case where a $6 \mathrm{~kg}$ weight spherical sample falling from $4.0 \mathrm{~m}$ height impacts the baffle plate at the incident angle $(\alpha)$ of $90^{\circ}$ (sample no. S-6-4-90). Generally speaking, the impact force increases with incident angle regardless of sample shape (sh), weight $(w)$, and drop height ( $h$; Fig. 5). The average impact force at incident angle of $90^{\circ}$ is about $15 \%$ higher than that at $60^{\circ}$, which in turn is about $14 \%$ higher than that at $30^{\circ}$. However, the impact force increases with drop height regard- 

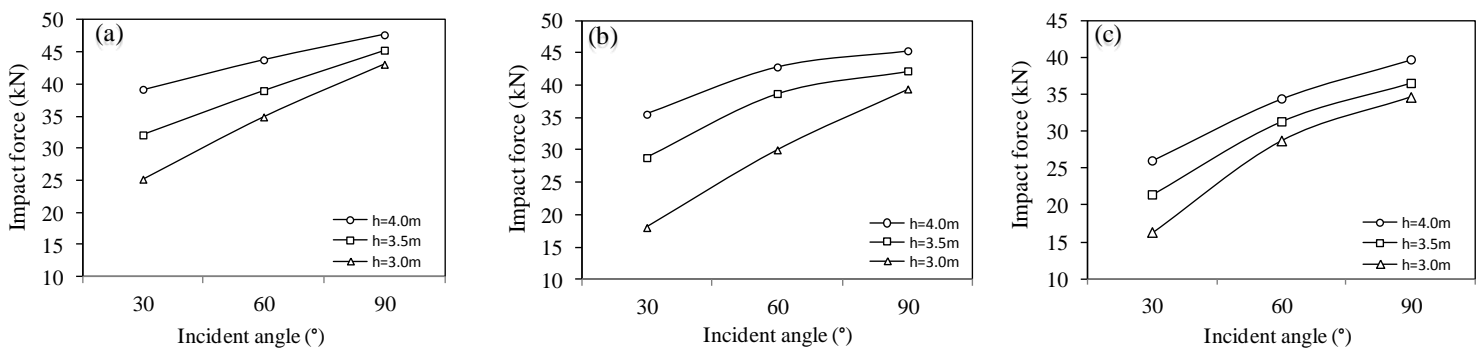

Figure 5. Measured impact force vs. incident angle for samples of different weights: sample weight $=$ (a) $6 \mathrm{~kg}$, (b) $5 \mathrm{~kg}$, and (c) $4 \mathrm{~kg}$.
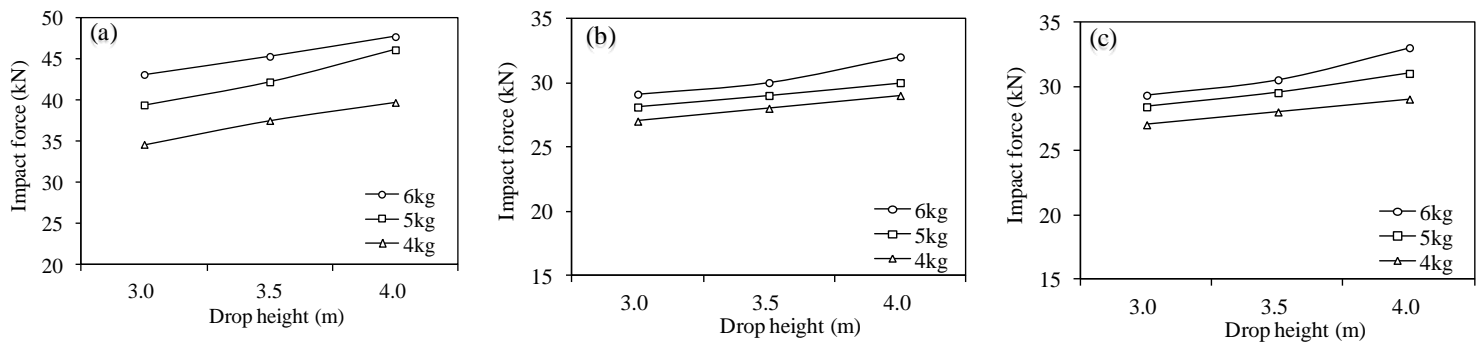

Figure 6. Impact force vs. drop height for samples of different shapes: (a) spherical, (b) cubic, and (c) cylindrical.
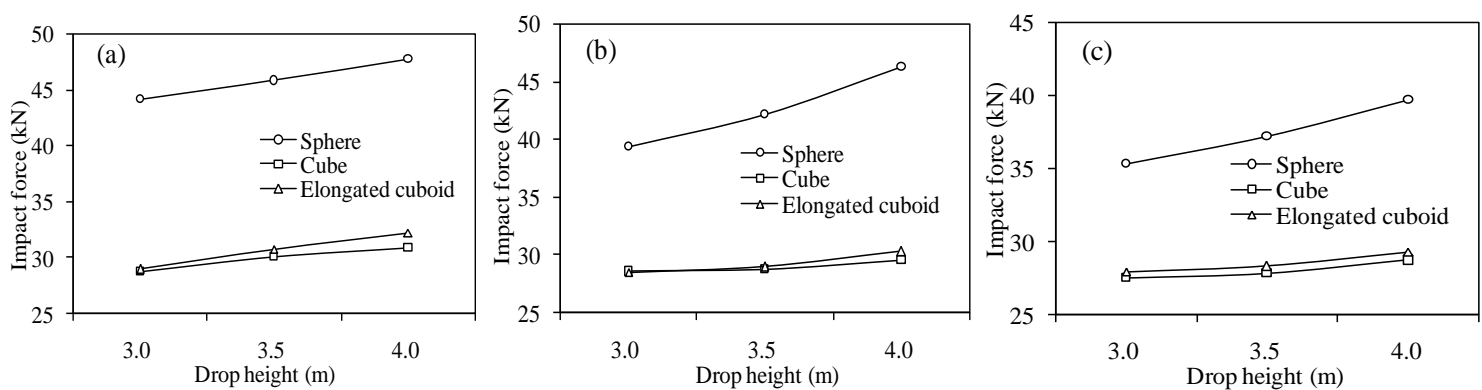

Figure 7. Impact force vs. drop height for samples with different weights: sample weight = (a) $6 \mathrm{~kg}$, (b) $5 \mathrm{~kg}$, and (c) $4 \mathrm{~kg}$.

less of other factors. On average, the impact force of rockfall from $4 \mathrm{~m}$ height is about $11 \%$ greater than that from $3.5 \mathrm{~m}$ height, which in turn is about $12 \%$ greater than that from $3.0 \mathrm{~m}$ height. The observation here is in good agreement with what was concluded by Pichler et al. (2005) and Tetsuya et al. (2004).

\subsection{Sample weight and shape}

As shown in Fig. 6, the impact force increases with sample weight. The average impact force for $6 \mathrm{~kg}$ weight samples is about $10 \%$ greater than that for $5 \mathrm{~kg}$ weight samples, which in turn is about $16 \%$ greater than that for samples of $4 \mathrm{~kg}$ weight. However, sample shape is found to impose strong effects on the measured impact forces. The spherical block had a higher rotation rate in its motion and less energy dissipated during its impact (Labiouse and Heidenreich, 2009). As shown in Fig. 7, spherical samples generate greater impact forces than cubes and elongated cuboids.

\subsection{Cushion layer}

The embankment is often used as a protective measure against rockfalls, and it is commonly composed of a core wall and cushion layer made of buffer material. In this study, gravel, sand, and clay are chosen as cushion materials and were evenly placed on the baffle with a thickness $(t)$ of 2 or $4 \mathrm{~cm}$. Spherical samples with a weight of $6 \mathrm{~kg}$ are used as the rockfall. Previous work (Schellenberg and Volkwein, 2008) has shown that the reaction forces could be reduced substantially with a cushion system. As shown in Fig. 8, such a thin cushion layer shows a significant effect in reducing impact forces. In general, clay cushion layers exhibit the strongest reduction effect among these three, while the effect by gravel cushion layer is the minimum, as the measured impact force reduced by a clay cushion layer is about half of that by a gravel cushion layer. However, the thickness of the cushion layer influences the extent of impact force reduction. The measured impact force after reduction by a $4 \mathrm{~cm}$ thick cush- 

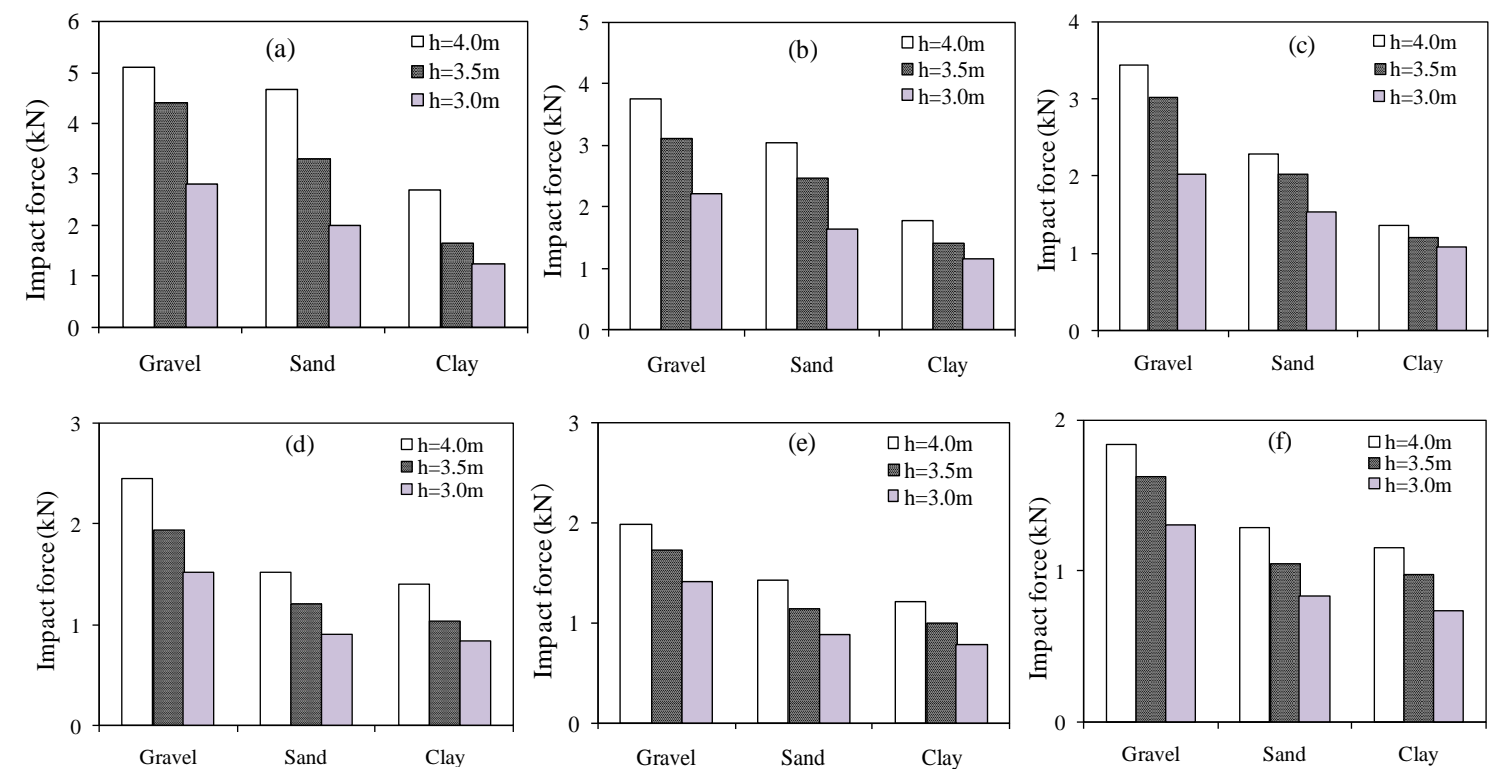

Figure 8. Influence of cushion layer on the impact force: (a) incident angle $\alpha=90^{\circ}$, thickness of cushion layer $t=2 \mathrm{~cm}$; (b) $\alpha=60^{\circ}$, $t=2 \mathrm{~cm}$; (c) $\alpha=30^{\circ}, t=2 \mathrm{~cm}$; (d) $\alpha=90^{\circ}, t=4 \mathrm{~cm}$; (e) $\alpha=60^{\circ}, t=4 \mathrm{~cm}$; and (f) $\alpha=30^{\circ}, t=4 \mathrm{~cm}$.
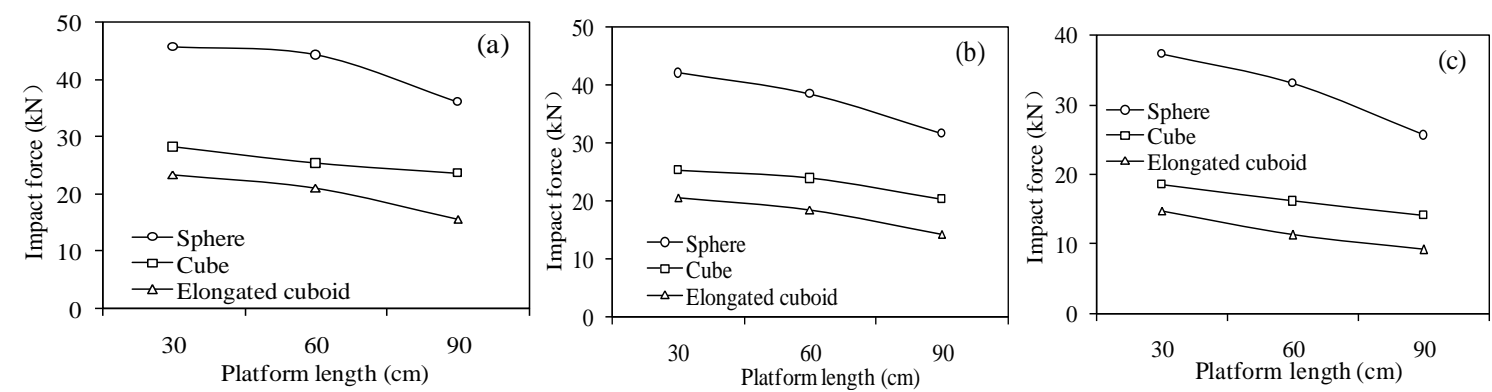

Figure 9. Influence of platform length on the impact force by different shapes of rockfalls: (a) $6 \mathrm{~kg}$, (b) $5 \mathrm{~kg}$, and (c) $4 \mathrm{~kg}$.

ion layer is about half of that after reduction by a $2 \mathrm{~cm}$ thick cushion layer.

In the case of right collision $\left(\alpha=90^{\circ}\right)$, the impact force of sample S-6-4-2C-90 (a spherical $6 \mathrm{~kg}$ weight sample falling from $4.0 \mathrm{~m}$ height onto the $2 \mathrm{~cm}$ thick clay cushion layer at an incident angle of $90^{\circ}$ ) was $2.9 \mathrm{kN}$, which is only about $11 \%$ of that from direct impact (sample S-6-4-90, without cushion layer). The impact force is reduced down to $1.6 \mathrm{kN}$ by a $4 \mathrm{~cm}$ thick clay cushion layer (sample S-6-4-4C-90). A $2 \mathrm{~cm}$ thick gravel cushion layer reduces the impact force from 38 down to $5 \mathrm{kN}$, making an reduction of about $86 \%$. In addition, the incident angle is found to influence the reduction of impact force by cushion layer. At an incident angle of $30^{\circ}$, the impact force of sample S-6-4-2C-30 is $1.4 \mathrm{kN}$, which is about half of sample S-6-4-2C-90 at the incident angle of $90^{\circ}$.

\subsection{Buffer platform}

For simulating the reduction effects by a platform on natural slope, a set of tests were conducted with platform lengths of
30, 60, and $90 \mathrm{~cm}$ (see Fig. $1 \mathrm{~b}$ for test set-up). Samples of different shapes and weights fell from a certain drop height $h$ of $4.0 \mathrm{~m}$. The incident angle was set to be $90^{\circ}$.

As shown in Fig. 9, a platform of $30 \mathrm{~cm}$ long may reduce the impact force by about $10 \%$. The 60 and $90 \mathrm{~cm}$ platforms can even reduce the impact force by 18 and $30 \%$ respectively. The longer the platform, the less the impact force measured. Another observation is that the reduction effect of platform is more obvious for rockfalls of cube and elongated cuboid than cubic ones, as the gradient of the trend line for cubic samples is the least in Fig. 9.

\subsection{Summary on the test results}

Based on the test results, several findings can be drawn: (1) the incident angle and drop height positively affect the impact force; (2) spherical rockfalls introduce higher impact force than cubes and elongated cuboids; (3) the impact force increases with weight of rockfall; (4) the cushion layer made of gravel, sand, or clay may significantly reduce the impact 
force, and the thicker the cushion layer, the greater the extent of reduction; and (5) a flat platform on the slideway can lead to a reduction of impact force, and the longer the platform, the more the impact force is reduced.

\section{Discussion}

\subsection{Impact velocity of rockfall}

According to the theorem of momentum, the rockfall impact force can come out from the following equation (Johnson, 1985; Han et al., 2004):

$F=m v / \Delta t$,

where $m$ is the mass of rockfall $(\mathrm{kg}), v$ is the instantaneous velocity of rockfall immediately approaching the baffle $\left(\mathrm{m} \mathrm{s}^{-1}\right), F$ is the impact force $(\mathrm{N})$, and $\Delta t$ is the time duration of the impact process (s). As the time duration $(\Delta t)$ is instant and $\Delta t$ are nearly consistent for all tests, Eq. (1) indicates positive correlation between weight and instantaneous velocity of rockfall and the impact force. This is consistent with the observation in Fig. 6, where the measured impact force increases with weight of rockfall.

The instantaneous velocity $(v)$ of rockfall immediately approaching the baffle plate was measured by means of a speedometer for all tests. As shown in Fig. 10, the measured impact velocity $(v)$ increases with drop height $(h)$ for a certain shape of rockfalls. The average impact velocity of $6 \mathrm{~kg}$ spherical samples falling from $4 \mathrm{~m}$ height is about 1.3 times as much as that from $3.0 \mathrm{~m}$ height. In addition, the impact velocity $(v)$ is found to be influenced by the shape of rockfalls. The impact velocity of $6 \mathrm{~kg}$ spherical rockfalls falling form $4.0 \mathrm{~m}$ height was $6.36 \mathrm{~m} \mathrm{~s}^{-1}$, while that of cubes and elongated cuboids from the same height was 3.71 and $3.48 \mathrm{~m} \mathrm{~s}^{-1}$ respectively. According to the regression of test results (Fig. 10), relationships between impact velocity $(v)$ and drop height $(h)$ are obtained as follows for different shapes of rockfall:

sphere:

$$
v=2.186 h^{0.778}(R=0.92),
$$

cube:

$v=0.958 h^{1.031}(R=0.93)$,

elongated cuboid:

$$
v=0.636 h^{1.164}(R=0.96) .
$$

The above equations indicate a positive exponential correlation between drop height and impact velocity of rockfalls, which is consistent with the theoretical formula deriving falling velocity $\left(v_{\mathrm{o}}\right)$ of a object from a certain height $(h)$ :

$v_{\mathrm{o}}=\sqrt{2 g h}=4.43 h^{0.5}$,

where $g$ is the gravity acceleration.

Figure 11 shows the normalized velocity $(\lambda)$, which is defined here as the ratio of impact velocity $(v)$ by Eq. (2) to falling velocity $\left(v_{\mathrm{o}}\right)$ by Eq. (3). It is found that with increase

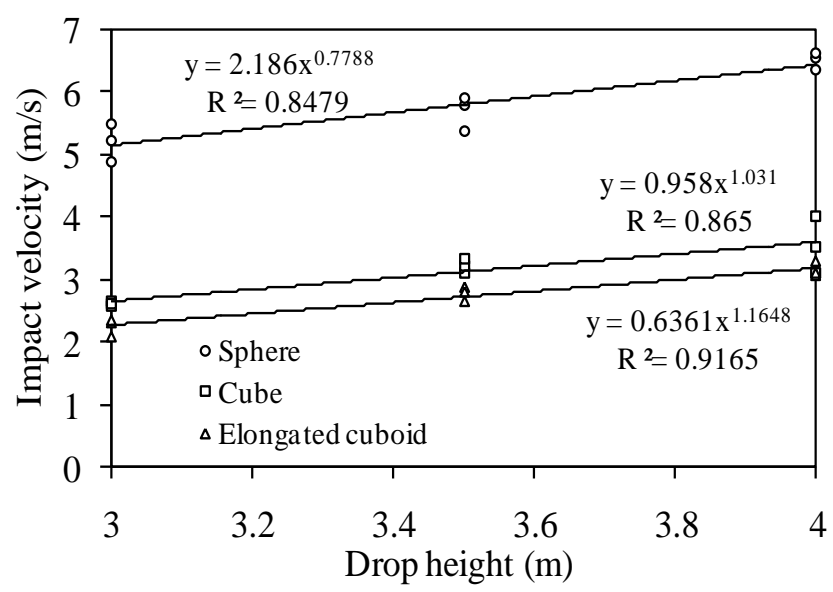

Figure 10. Positive exponential correlation between impact velocity $(v)$ and drop height $(h)$.

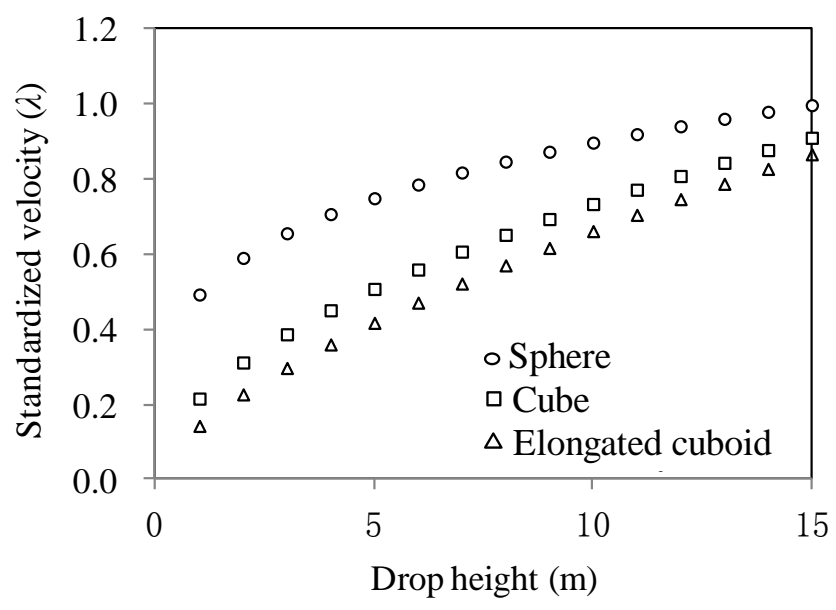

Figure 11. Normalized velocity $(\lambda)$ of rockfalls of different shapes.

in drop height, the impact velocity $(v)$ is approaching the theoretical falling velocity $\left(v_{\mathrm{o}}\right)$, regardless of the shape of rockfalls. However, at small drop heights, there are big differences between them. In addition, a spherical rockfall exhibits the highest normalized velocity, indicating its approximation of the theoretical values especially at a big drop height. In the cases of cubes and elongated cuboids, the low values of $\lambda$ indicate the influences of shape of rockfall on the impact velocity. Among the considered three types, the elongated cuboid contributes the most to reduction of impact velocity.

Nonetheless, the instantaneous impact velocity is significantly reduced by a buffer platform on the slideway. The impact velocity of $6 \mathrm{~kg}$ spherical rockfalls falling form $4.0 \mathrm{~m}$ height was $5.19,4.68$, and $4.11 \mathrm{~m} \mathrm{~s}^{-1}$ when the buffer platform is 30,60 , and $90 \mathrm{~cm}$ long respectively. It is seen in Fig. 12 that the longer the buffer platform, the lower the impact velocity. This is in good agreements with previous researches. Huang et al. (2010) and Okura et al. (2000), for instance, carried out field trials of rockfall travelling through a 

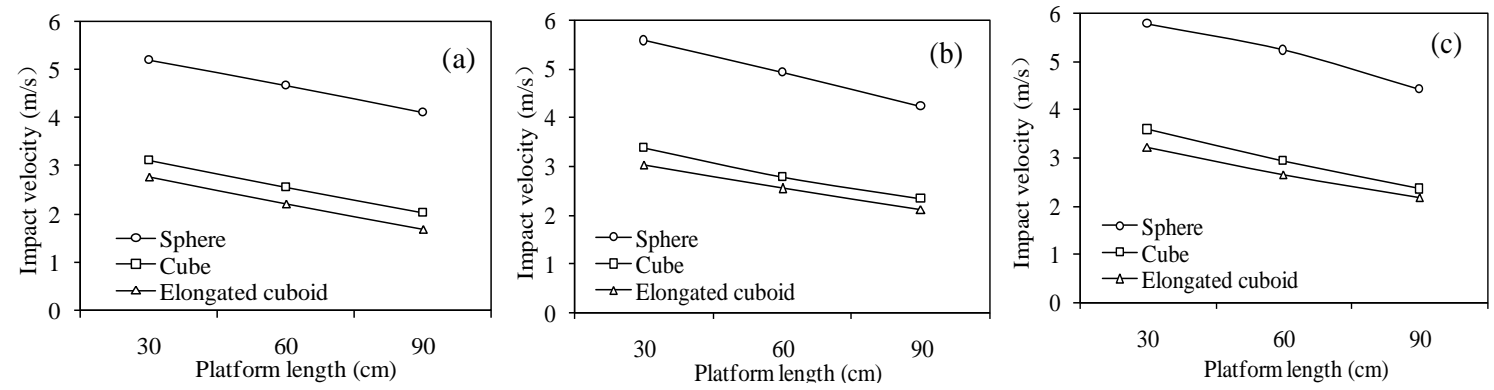

Figure 12. Influence of platform length on the impact velocity of rockfalls of different shapes and weights: (a) $6 \mathrm{~kg}$, (b) $5 \mathrm{~kg}$, and (c) $4 \mathrm{~kg}$.

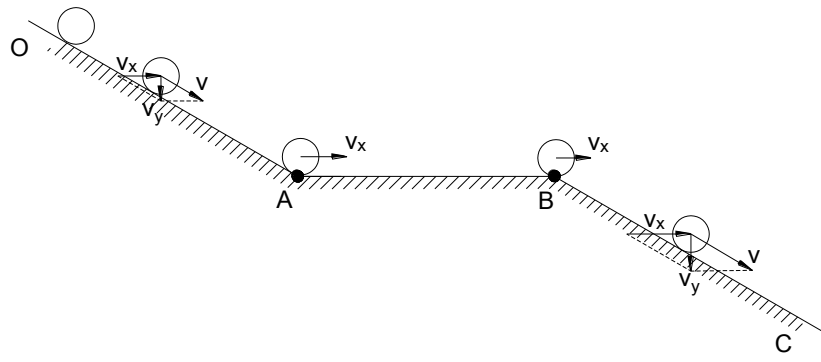

Figure 13. Change of rockfall velocity along a slideway with a platform (length of the vector indicates the absolute velocity values).

slideway with platform of different lengths and indicated that the platform length reduces the impact force of rockfalls.

Figure 13 demonstrates the change process of rockfall velocity during the falling process. At point $\mathrm{O}$ (the start point), the velocity $(v)$ is equal to 0 . It gets greater when the rockfall runs towards point A due to the gravity. At point A, the component in vertical direction $\left(v_{y}\right)$ becomes 0 due to the upward counterforce by the platform, leaving the component in the horizontal direction $\left(v_{x}\right)$ alone. $v_{x}$ may get smaller due to energy dissipation by friction along the platform. After point $\mathrm{B}, v_{y}$ starts increasing from 0 due to the gravity acceleration, leading to increase in $v$ and $v_{x}$. The process above indicates that the platform works as a barrier to eliminate the vertical component $v_{y}$ of the rockfall velocity $v$ and dissipate the kinetic energy of rockfall by friction, which leads to an overall reduction of rockfall velocity.

Regression analysis taking the measured impact velocity $(v)$ and weight of rockfall $(w)$ as independent variables and the measured impact force as dependent gives the following nonlinear relationship (Eq. 4):

$F=11.2 w^{0.216} v^{0.502}(R=0.87)$.

The above exponential equation indicates that the impact force is positive to weight and impact velocity of rockfall. Thus, the impact velocity is dependent not only upon the drop height but also upon the shape of rockfall and the platform length. However, in the present engineering practice, both rockfall shape and the platform are not taken into account during designing of protection measures; instead an equivalent spherical object is normally used. This is thought to overestimate the impact force.

\subsection{Cushion layer}

According to the law of energy conservation, the kinetic en$\operatorname{ergy}(\bar{E})$ of the rockfall, which is equal to $1 / 2 m v^{2}$, is transferred into the strain energy $(U)$ of the buffer layer during the impacting process. The strain energy can be calculated according to the following theoretical formula:

$\bar{E}=U=\iiint_{V} u_{0}\left(\varepsilon_{i j}\right) \mathrm{d} V$,

where $u_{0}\left(\varepsilon_{i j}\right)$ is the density of strain energy i.e. the strain energy per unit volume.

According to the Green formula,

$\frac{\partial u_{0\left(\varepsilon_{i j}\right)}}{\partial \varepsilon_{i j}}=\sigma_{i j}$,

by integral there are

$\int_{0}^{u}(\varepsilon) \mathrm{d} u_{0}=\int_{0}^{\varepsilon} \sigma_{i j} \mathrm{~d} \varepsilon_{i j}=u_{0}\left(\varepsilon_{i j}\right)-u_{0}(0)$,

where $u_{0}\left(\varepsilon_{i j}\right)$ and $u_{0}(0)$ is the strain energy density after and before the deformation respectively. Taking $u_{0}(0)$ as 0 ,

$u_{0}\left(\varepsilon_{i j}\right)=\int_{0}^{\varepsilon} \sigma_{i j} \mathrm{~d} \varepsilon_{i j}$

Considering $\bar{\sigma}$ as the average stress of cushion material during deformation by impaction of rockfall, Eq. (8) can be simplified and reformed as

$u_{0}=\frac{1}{2} \bar{\sigma} \varepsilon=\frac{\bar{\sigma}^{2}}{2 E}$,

where $\varepsilon$ and $E$ are the strain and elastic modulus of cushion material respectively. 
The total strain energy (Eq. 5) of the cushion layer therefore can be expressed as Eq. (10):

$U=h \cdot S \cdot \frac{\bar{\sigma}^{2}}{2 E}$,

where $h$ is the thickness of the cushion layer and $S$ is the rockfall-cushion layer contact area.

Combining Eqs. (5) and (10) gives

$\bar{\sigma}=\sqrt{\frac{2 E U}{h S}}=\sqrt{\frac{2 E \bar{E}}{h S}}=\sqrt{\frac{E m v^{2}}{h S}}$.

According to Eq. (11), for a certain impaction a thick cushion layer made of material with low elastic modulus would introduce a relatively low stress in the cushion layer. The above derivation explains the greater buffering effect by a layer of clay than that by gravel and explains the contribution of cushion layer thickness (Fig. 8). However, the contact area changes with the shape of rockfall. A spherical rockfall minimizes the contact area, which maximizes the stress and therefore the measured impact force.

\section{Conclusions}

According to the foregoing discussion, main conclusions can be drawn as follows.

The impact force is positively exponential to the weight of rockfall and instantaneous impact velocity of the rockfall approaching the protective measures. The impact velocity is in turn dominated not only by the drop height but also by the shape of rockfall as well as platform on the slideway. A platform reduces the impact velocity by eliminating the vertical component of falling velocity and minimizing the horizontal component. A spherical rockfall may introduce an impact velocity close to that from theoretical calculation.

A layer of cushion material on the protection measures may reduce the impact force to a greater extent. The reduction effects are dominated by the cushion material and the thickness of the cushion layer. The thicker the cushion layer, the greater the reduction effect and therefore the less the impact force. The stiffer the cushion material, the less the reduction effect and the greater the impact force.

The determination of impact force is crucial in designing protection measures for rockfalls. The present study depicts the influences of drop height and weight of rockfall, platform on the slideway, and buffer layer on the protection measures, which indicate that the impact force may be misestimated by taking no consideration for rockfall shape, platform, and buffer layer. Due to the limitation of the experiments, the bouncing and rolling behaviour of rockfalls was not considered in this study. Further investigation is desired to verify and improve the relationships derived from this study in order to cover a broader natural situation.
Acknowledgements. This study was supported by the National Natural Science Foundation of China (nos. 51309176 and 40972195), Science and Technology Innovation Team of Sichuan Province (no. 2011JTD012), Ministry of Land and Resources of China (no. 201211055), and independent research of the State Key Laboratory of Geohazard Prevention and Geoenvironment Protection (no. HGY-2012-08).

Edited by: T. Glade

Reviewed by: J. Huo and one anonymous referee

\section{References}

Abdul, Q. B. and Norimitsu, K.: Impact response of RC rock-shed girder with sand cushion under falling load, J. Nuclear Eng. Design, 240, 2626-2632, 2010.

Azzoni, A., Barbera, G., and Zaninetti, A.: Analysis and prediction of rockfalls using a mathmatical model, Int. J. Rock Mech. Mining Sci., 32, 709-725, 1995.

Giani, G., Giacomini, A., and Migliazza, M.: Experimental and theoretical studies to improve rock fall analysis and protection work design, Int. J. Rock Mech. Rock Eng., 37, 369-389, 2004.

Glover, J., Bartelt, P., Petley, D., and Rosser, N.: Characteristic rockfall runout behaviour of three end-member rock forms, J. Geophys. Res., 16, EGU2014-16910, 2014.

Han, W., Jin, D. P., and Hu, H. Y.: Dynamics of an oblique-impact vibrating system of two degrees of freedom, J. Sound Vibration, 275, 795-822, 2004.

Huang, R. Q., Liu, W. H., Zhou, J. P., and Pei, X. J.: Experimental field study of movement charateristics of rock blocks falling down a slope, J. Earth Sci., 21, 330-339, 2010.

Japan Road Association: Handbook for rockfall measures, Japan Road Association, Tokyo, Japan, 20-23, 2000.

Jean, P. M. and Pascal, P.: Rock fall impact on reinforced concrete slab: an experimental approach, Int. J. Impact Eng., 31, 169-183, 2005.

Johnson, K. L.: Contact mechanics, Cambridge University Press, London, England, 399-409, 1985.

Kawahara, S. and Muro, T.: Effects of dry density and thickness of sandy soil on impact response due to rockfall, J. Terramechanics, 43, 329-340, 2006.

Kishi, N.: Absorbing performance of sand cushion and threelayered absorbing system, Proc. Third SILOS, Singapore, 51-56, 1999.

Kishi, N., Konno, H., and Ikeda, K.: Prototype impact tests on ultimate impact resistance of PC rock-sheds, Int. J. Impact Eng., 27, 969-985, 2002.

Labiouse, V.: Experimenta1 study of rock sheds impacted by rock blocks, J. Struct. Eng. Int., 3, 171-175, 1996.

Labiouse, V. and Heidenreich, B.: Half-scale experimental study of rockfall impacts on sandy slopes, Nat. Hazards Earth Syst. Sci., 9, 1981-1993, doi:10.5194/nhess-9-1981-2009, 2009.

Okura, Y., Kitahara, H., Sammori, H., and Kawanami, A.: The effects of rockfall volume on runout distance, J. Eng. Geol., 58, 109-124, 2000.

Peila, D., Polizza, S., and Sassudelli S.: Evaluation of behaviour of rockfall retaining nets by full scale tests, Int. J. Rock Mech. Rock Eng., 31, 1-24, 1998. 
Peila, D., Oggeri, C., and Castiglia, C.: Ground reinforced embankments for rockfall protection: design and evaluation of full scale tests, J. Landslides, 4, 255-265, 2007.

Pichler, B., Hellmich, C., and Mang, H. A.: Impact of rocks onto gravel design and evaluation of experiments, Int. J. Impact Eng., 31, 560-578, 2005.

Pichler, B., Hellmich, C., and Mang, H. A.: Loading of a gravelburied steel pipe subjected to rockfall, J. Geotec. Geoenviron. Eng., 132, 1465-1473, 2006.

Plassiard, J. and Donze F.: Rockfall impact parameters on embankments: A discrete element method analysis, J. Struct. Eng. Int., 19, 333-341, 2009.

Schellenberg, K., Volkwein, A., Roth, A., and Vogel, T.: Large-scale impact tests on rock fall galleries, Proceedings of the 7th International Conference on Shock and Impact Loads on Structures, Beijing, China, 10-19 October 2007, 497-504, 2007.
Schellenberg, K., Volkwein, A., Denk, M., and Vogel, T.: Falling weight tests on rock fall galleries with cushion layers, Interdisciplinary Workshop on Rockfall Protection, Morschach, Switzerland, 23-25 June 2008, 6, 23-25, 2008.

Stoffel, M. and Perret, S.: Reconstructing past rockfall activity with tree rings, J. Dendrochronologia, 24, 1-15, 2006.

Tetsuya, S., Naoki, S., and Yozo, O.: The effect of rockfall simulation due to impact angle, Proeeedings of the Symposium on Rock Mech., 33, 337-342, 2004.

Vilajosana, I., Suriñach, E., Abellán, A., Khazaradze, G., Garcia, D., and Llosa, J.: Rockfall induced seismic signals: case study in Montserrat, Catalonia, Nat. Hazards Earth Syst. Sci., 8, 805-812, doi:10.5194/nhess-8-805-2008, 2008. 